\title{
Stable, long-term, spatial memory in young and aged rats achieved with a one day Morris water maze training protocol
}

\author{
Ruth M. Barrientos, Meagan M. Kitt, Heather M. D'Angelo, Linda R. Watkins, \\ Jerry W. Rudy, and Steven F. Maier \\ Department of Psychology and Neuroscience, Center for Neuroscience, University of Colorado Boulder, Boulder, \\ Colorado 80309-0345, USA
}

\begin{abstract}
Here, we present data demonstrating that a $1 \mathrm{~d}$ Morris water maze training protocol is effective at producing stable, longterm spatial memory in both young ( 3 mo old) and aged ( 24 mo old) F344xBN rats. Four trials in each of four sessions separated by a $2.5 \mathrm{~h}$ ISI produced robust selective search for the platform 1 and $4 \mathrm{~d}$ after training, in both age groups. A $1 \mathrm{~h}$ ISI protocol did not produce good retention. Also, compressing the trials into just two sessions separated by a $2.5 \mathrm{~h}$ ISI produced limited retention in only young rats.
\end{abstract}

One of the challenges to studying the impact of aging on memory is developing tasks that can be learned equally well regardless of age but reveal memory impairments when the retention interval is varied. This property is critical for allowing the identification of how the neural substrates that support memory change over the life span. The Morris place-learning task has proven valuable for study of the neural systems that support spatial memory. However, although rodents are able to learn this task quickly (one session) retention is generally poor. For example, Bolding and Rudy (2006) reported that following a single session of training rats displayed good retention when tested within $10 \mathrm{~min}$, but retention greatly deteriorated when the interval was extended to $4 \mathrm{~h}$ or more. However, Bolding and Rudy found that by manipulating the interval separating blocks of training trials, long-term retention of this memory was dramatically improved. Specifically, a $2 \mathrm{~h}$ intersession interval (ISI) produced robust long-term spatial memory 24 h later.

A primary interest of our laboratory is to understand how aging alters the effects of inflammatory challenges such as infection or surgery on hippocampal-dependent learning and memory (Barrientos et al. 2006, 2012). Each of these challenges produces a time-limited neuroinflammatory response, lasting between 4 and $8 \mathrm{~d}$ (Barrientos et al. 2009a, 2012). Three of these days are marked by fever and lethargy (Barrientos et al. 2009b), factors that confound interpretation of the task (Cunningham and Sanderson 2008), and thus training cannot begin before day 4 . This time constraint poses a challenge for conducting behavioral experiments designed to test more than one behavioral task (e.g., contextual fear conditioning and Morris water maze) in the same animal, as each of these tasks can take up to $7 \mathrm{~d}$ to complete. Thus, the development of a $1 \mathrm{~d}$ version of the Morris water maze task would prove useful. Therefore, we conducted a set of experiments to determine whether the general approach Bolding and Rudy (2006) used to enhance retention in young rats could be used to increase retention in older rats and thereby provide a paradigm that can be used to determine whether challenges that influence neuroinflammation differentially effect the retention

\section{Corresponding author: ruth.barrientos@colorado.edu}

Article is online at http://www.learnmem.org/cgi/doi/10.1101/lm.043489. 116. performance of young and older rats trained on the Morris water maze task. These experiments were successful in increasing the retention performance of both young and older rats, and the results are reported below.

Subjects were male F344xBN F1 rats obtained from Envigo through the National Institute on Aging. Rats were 3 or 24 mo old, weighing $\sim 275$ or $550 \mathrm{~g}$, respectively. The F344xBN strain of rat has a $90 \%$ survival rate at 24 mo of age, and should not be confused with Fischer 344 rats, which have a 50\% survival at this age. Our previous work has shown that unchallenged F344xBN rats at this age do not show impaired function on the standard Morris water maze protocol compared with 3 mo old controls (Barrientos et al. 2006). Age-matched rats were housed two to a cage $(52 \mathrm{~L} \times 30 \mathrm{~W} \times 21 \mathrm{H}, \mathrm{cm})$, animal colony was maintained at $22 \pm 1^{\circ} \mathrm{C}$ on a 12-h light-dark cycle (lights on at 07:00 h), and rats were allowed free access to food and water, and were given at least $1 \mathrm{wk}$ to acclimate to colony conditions before experimentation began. All procedures were conducted during the light phase. All experiments were conducted in accordance with protocols approved by the University of Colorado Animal Care and Use Committee. All efforts were made to minimize the number of animals used and their suffering.

The water maze consisted of a circular galvanized steel pool $\sim 117 \mathrm{~cm}$ in diameter and $58 \mathrm{~cm}$ deep. A movable escape platform constructed of a Plexiglas base column having a height of $43 \mathrm{~cm}$ and topped by a round platform $15 \mathrm{~cm}$ in diameter, was placed in one quadrant of the pool and was maintained there throughout acquisition of the task. The water was filled to a height of $47 \mathrm{~cm}$ and maintained at $26 \pm 1{ }^{\circ} \mathrm{C}$, and rendered opaque with nontoxic, water-soluble white paint. Water level was maintained at $2 \mathrm{~cm}$ above the platform's surface. There were many prominent visual cues that remained constantly positioned around the testing room throughout the study, to serve as distal spatial cues to the location of the platform. No local cues were present within the pool.

(C) 2016 Barrientos et al. This article is distributed exclusively by Cold Spring Harbor Laboratory Press for the first 12 months after the full-issue publication date (see http://learnmem.cshlp.org/site/misc/terms.xhtml). After 12 months, it is available under a Creative Commons License (AttributionNonCommercial 4.0 International), as described at http://creativecommons. org/licenses/by-nc/4.0/. 
A stopwatch was used to measure latency to reach the platform during acquisition trials. A video camera was mounted on the ceiling to record the rats' swim patterns during the probe trials and individuals blinded to group assignment scored the videos to obtain the retention data.

\section{Experiment 1}

To determine a protocol that would produce good spatial reference memory at $24 \mathrm{~h}$, two protocols were examined. All animals received four trials per session and four sessions throughout the day, for a total of 16 acquisition trials. Depending on group assignment the intersession interval (ISI) was either 1 or $2.5 \mathrm{~h}$. Each training trial started by placing the rat into the water at any of four randomly chosen quadrants with its snout facing the wall of the pool. The rat was allowed to search for the escape platform for up to $60 \mathrm{sec}$ and when located allowed to remain on the platform for $15 \mathrm{sec}$. If the rat failed to find the platform within $60 \mathrm{sec}$ it was placed on the platform. The rat was returned to a holding cage until the next trial. Rats were run in squads of $8-12$ at a time. The intertrial interval was $\sim 3-8 \mathrm{~min}$. At the end of each session, rats were dried with a towel, placed back into their home cage and returned to their colony until the beginning of the next session.

Twenty-four hours following the last acquisition trial the rats were given a probe trial retention test. The platform was removed from the pool and the rat was placed in the pool and allowed to swim freely for $60 \mathrm{sec}$. Several measures were used to assess retention on this probe trial: (a) Dwell time in each of the pool's quadrants, (b) latency to swim to the platform's original location, and (c) total number of times the rat crossed the original platform location.

The acquisition performance of young and aged rats was quite similar (Fig. 1A). Both age groups rats showed a significant reduction in latencies to reach the platform over the four sessions [young: $F_{(3,40)}=32.93, P<0.0001$; aged: $\left.\left(F_{(3,40)}=37.29, P<0.0001\right)\right]$, and those trained with the $2.5 \mathrm{~h}$ ISI protocol were on average faster to reach the platform than those trained with the $1 \mathrm{~h}$ ISI protocol [young: $F_{(1,40)}=14.89, P=0.0004$; aged: $\left(F_{(1,40)}=5.49, P=0.024\right]$. There was a main effect of age across all sessions $\left(F_{(1,3)}=8.44, P=0.005\right)$, which is likely to be due to a slower swim speed in the aged rats, however this cannot be confirmed due to the lack of path length data.

Retention performance is presented in Figure $1 \mathrm{~B}-\mathrm{E}$. Young and aged groups were analyzed separately on each training protocol to more accurately assess the effectiveness of the training protocols to produce good spatial memory. The ISI influenced retention performance of both young and aged rats. In general, rats in the $1 \mathrm{~h}$ ISI group displayed very poor retention, as they did not preferentially dwell in the target quadrant. Young adult rats trained with the $1 \mathrm{~h}$ ISI protocol spent more time in the target quadrant (Q4) than Q3 $(P<0.0001)$, but none of the other quadrants $(P>$ 0.05); (Fig. 1B, left). Aged rats did not spend significantly more time in the target quadrant (Q4) than any of the other quadrants $(P>0.05)$; (Fig. 1C, left). In contrast, both age groups trained with the 2.5 ISI protocol spent significantly more time in the target quadrant than every other quadrant (all $P$ values $<0.01$ ) (Fig. $1 \mathrm{~B}, \mathrm{C}$, right).

Rats trained with the $1 \mathrm{~h}$ ISI showed longer latencies to first reach the platform location during the probe trial compared with those trained with the $2.5 \mathrm{~h}$ ISI, although this was only statistically significant in the aged rats $\left(t_{(12)}=2.65, P<0.05\right.$ ) (Fig. $2 \mathrm{D})$. Finally, both young and aged groups trained with the $2.5 \mathrm{~h}$ ISI made a greater number of platform crosses than those trained with the $1 \mathrm{~h}$ ISI (Young: $t_{(10)}=3.21, P<0.01$; Aged: $t_{(12)}=5.22$, $P<0.001)$.

\section{Experiment 2}

The first experiment revealed excellent $24 \mathrm{~h}$ retention when rats were trained with a $2.5 \mathrm{~h}$ ISI. The second experiment was designed to replicate and extend this finding. To do this the ISI was $2.5 \mathrm{~h}$ for all rats. Rats then were tested either 1 or $4 \mathrm{~d}$ after training.
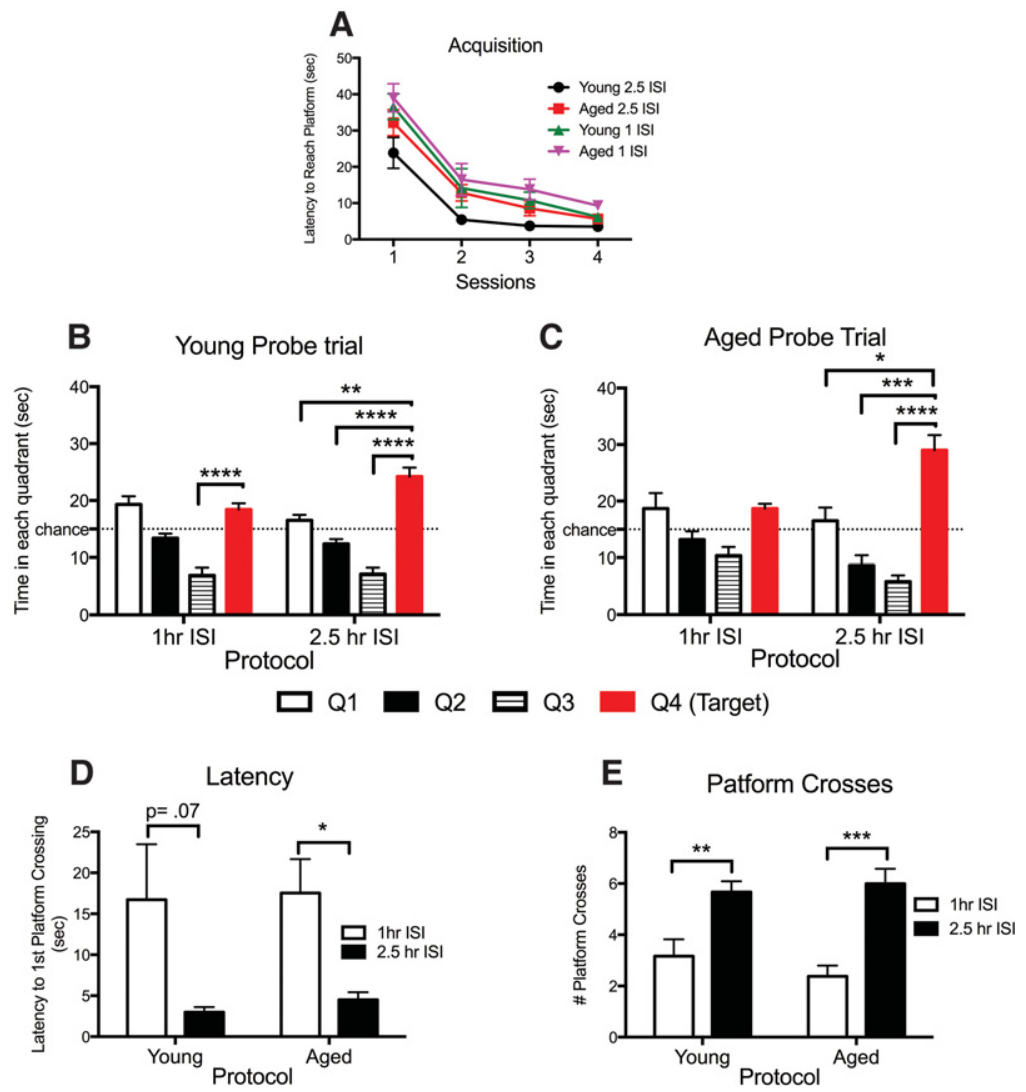

Figure 1. Acquisition and $24 \mathrm{~h}$ retention data from the $1 \mathrm{~h}$ versus $2.5 \mathrm{~h}$ ISI protocol. $(A)$ Latency to reach the platform during training in young and aged rats that were trained with the $1 \mathrm{~h}$ versus 2.5 $\mathrm{h}$ ISI. (B) Amount of time young rats spent in each quadrant during the probe trial $24 \mathrm{~h}$ post-training with the $1 \mathrm{~h}$ versus $2.5 \mathrm{~h}$ ISI protocol. (C) Amount of time aged rats spent in each quadrant during the probe trial $24 \mathrm{~h}$ post-training with the $1 \mathrm{~h}$ versus $2.5 \mathrm{~h}$ ISI protocol. $(D)$ Latency to first platform crossing in young and aged rats trained with the $1 \mathrm{~h}$ versus $2.5 \mathrm{~h}$ ISI protocol. $(E)$ Number of platform crossings of young and aged rats trained with the $1 \mathrm{~h}$ versus $2.5 \mathrm{~h}$ ISI protocol. Data are mean + SEM. $(*) P<0.05 ;(* *) P<0.01 ;(* * *) P<0.001 ;(* * *) P<0.0001$. 

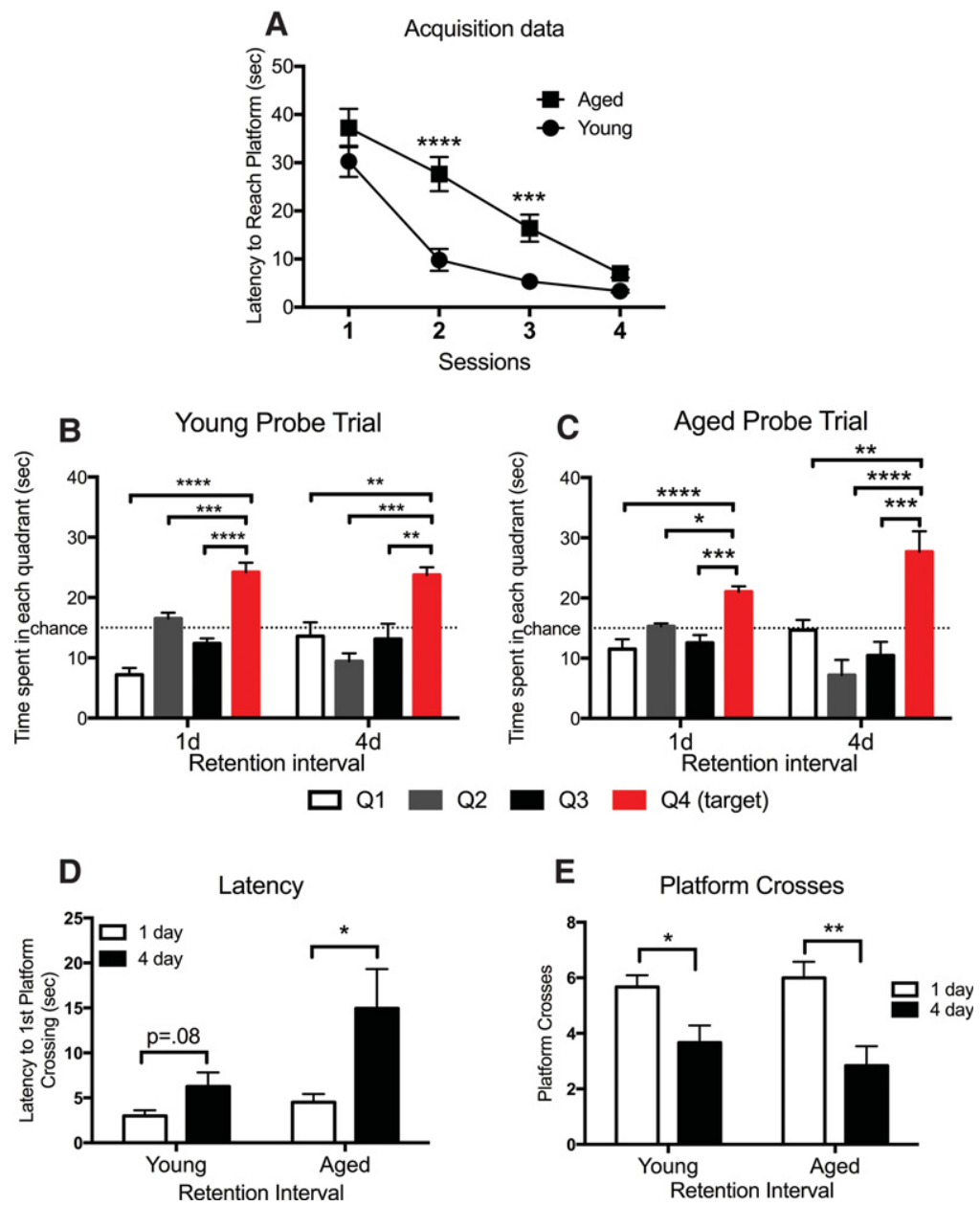

Figure 2. Acquisition and $24 \mathrm{~h}$ and $4 \mathrm{~d}$ retention data from the $2.5 \mathrm{~h} \mathrm{ISI} \mathrm{protocol}$. (A) Latency to reach the platform during training in young and aged rats. (B) Amount of time young rats spent in each quadrant during the probe trial $24 \mathrm{~h}$ and $4 \mathrm{~d}$ post training. (C) Amount of time aged rats spent in each quadrant during the probe trial $24 \mathrm{~h}$ and $4 \mathrm{~d}$ post training. $(D)$ Latency to first platform crossing in young and aged rats tested at the $24 \mathrm{~h}$ and $4 \mathrm{~d}$ retention interval. (E) Number of platform crossings of young and aged rats tested at the 24-h and 4-d retention interval. Data are mean + SEM. $\left({ }^{*}\right) P<0.05 ;\left(^{* *}\right) P<$ $0.01 ;(* *) P<0.001 ;(* * *) P<0.0001$.

Acquisition latencies produced a significant age $\times$ session interaction $\left(F_{(3,60)}=3.032, P<0.05\right)$ (Fig. 2A). Latencies to reach the platform were significantly reduced over the four session $\left(F_{(3,60)}=49.85, P<0.0001\right)$. As in Experiment 1 , there was a main effect of age $\left(F_{(1,20)}=18.31, P=0.0004\right)$, with aged rats being slower to reach the platform on sessions $2(P<0.0001)$ and 3 $(P<0.05)$ than were their younger counterparts, but latencies were no longer different by session 4 .

Analyses revealed that this $1 \mathrm{~d}$ training protocol produced good spatial memory at both the 1 and $4 \mathrm{~d}$ retention intervals, in both young and aged rats. As evident in Figure 2B,C, post-hoc analyses revealed that rats spent significantly more time in the target quadrant (Q4) than each of the other quadrants $(1 \mathrm{~d}$ : all $P$ values $<0.05 ; 4$ d: all $P$ values $<0.01)$. Young rats showed a similar latency to first reach the platform location during the $4 \mathrm{~d}$ compared with the $1 \mathrm{~d}$ retention trial $\left(t_{(10)}=1.94, P>0.05\right)$ (Fig. $\left.2 \mathrm{D}\right)$, however, aged rats took a bit longer during the longer retention interval $\left(t_{(10)}=2.33, P<0.05\right)$ (Fig. $\left.2 D\right)$. Both young and aged groups showed fewer platform crosses in the $4 \mathrm{~d}$ compared with the $1 \mathrm{~d}$ retention trial (Young: $t_{(10)}=2.68, P<0.05$; Aged: $t_{(10)}=$ $3.48, P<0.01)$.

\section{Experiment 3}

An important goal of this research was to identify an efficient training protocol for producing a long lasting spatial memory. For this reason, in Experiment 3 we distributed the 16 training trials over only two sessions separated by a $2.5 \mathrm{~h}$ ISI. Rats were tested either 1 or 4 d later. Bolding and Rudy (2006) had showed that a similar training protocol produced good retention $24 \mathrm{~h}$ later.

Acquisition latencies (Fig. 3A) to reach the platform were significantly reduced over the two sessions $\left(F_{(1,14)}=\right.$ $69.07 P<0.0001)$, but there was no statistical difference between the two age groups $\left(F_{(1,14)}=4.54 P=0.086\right)$.

Analyses revealed that this compressed training protocol produced good spatial memory at the $1 \mathrm{~d}$, but not the $4 \mathrm{~d}$ retention interval for young rats, and did not produce good memory in aged rats at either retention interval (Fig. 3B,C). At the $1 \mathrm{~d}$ retention test young rats spent significantly more time in the target quadrant (Q4) than each of the other quadrants (all $P$ values $<0.05$ ). However, at the $4 \mathrm{~d}$ test young rats spent more time in the target quadrant only compared with Q3 $(P<0.05)$, but not compared with Q1 or Q2 $(P>$ 0.05).

During the $1 \mathrm{~d}$ retention test aged rats spent more time in the target quadrant than Q2 $(P<0.01)$ and Q3 $(P<$ $0.001)$, but not than Q1 $(P>0.05)$. At the $4 \mathrm{~d}$ test they did not spend more time in Q4 than any other quadrant $(P>0.05)$.

Latencies to first reach the platform location did not differ among young rats across the two retention trials $\left(t_{(14)}=\right.$ 0.55, $P>0.05$ ) (Fig. 3D), however, aged rats took significantly longer to find the platform location at the $4 \mathrm{~d}$ test $\left(t_{(14)}=2.76, P<0.05\right.$; Fig. $3 D)$. Young rats made an equal number of platform crossings across the two retention intervals $\left(t_{(14)}=0.77, P>0.05\right)$, but aged rats made significantly fewer crossings at the $4 \mathrm{~d}$ interval test compared with the shorter retention interval $\left(t_{(14)}=2.96\right.$, $P<0.05)$.

This study revealed that 16 training trials distributed over four sessions with an ISI of either 1 or $2.5 \mathrm{~h}$ produced good acquisition in both young and aged rats. However, retention 24 $\mathrm{h}$ later was excellent only when the ISI was $2.5 \mathrm{~h}$. The $1 \mathrm{~h}$ ISI produced very poor retention in both age groups. These findings highlight the importance of using a probe trial to assess spatial memory, rather than relying solely on acquisition data. An early paper that used a $1 \mathrm{~d}$ training protocol (3 fourblock trials separated by $1 \mathrm{~h}$ ) used acquisition times to assess cognitive deficits associated with brain damage, but a retention probe trial was not performed, thus likely underestimating any deficits (Kraemer et al. 1996). The $2.5 \mathrm{~h}$ ISI yielded excellent retention, as measured by dwell times, in both aged groups even when the retention interval was extended to $4 \mathrm{~d}$. However, both age groups showed longer latencies to the first 


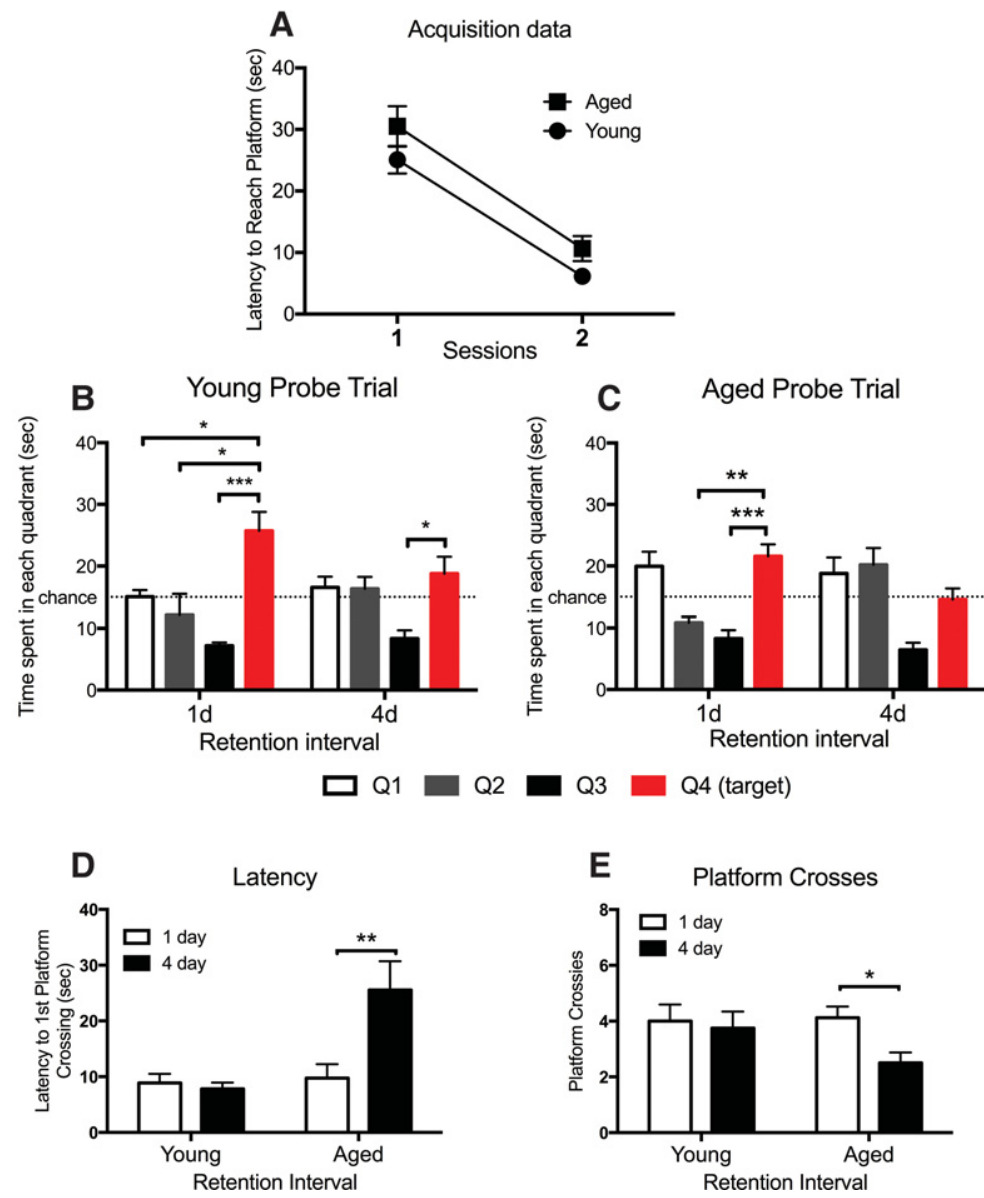

Figure 3. Acquisition and 24-h and 4-d retention data from the compressed protocol (two 8-trial sessions with a $2.5 \mathrm{~h} \mathrm{ISI).} \mathrm{(A)} \mathrm{Latency} \mathrm{to} \mathrm{reach} \mathrm{the} \mathrm{platform} \mathrm{during} \mathrm{training} \mathrm{in} \mathrm{young} \mathrm{and} \mathrm{aged} \mathrm{rats.}(B)$ Amount of time young rats spent in each quadrant during the probe trial $24 \mathrm{~h}$ and $4 \mathrm{~d}$ post training. (C) Amount of time aged rats spent in each quadrant during the probe trial $24 \mathrm{~h}$ and $4 \mathrm{~d}$ post training. (D) Latency to first platform crossing in young and aged rats tested at the $24 \mathrm{~h}$ and $4 \mathrm{~d}$ retention interval. (E) Number of platform crossings of young and aged rats tested at the $24 \mathrm{~h}$ and $4 \mathrm{~d}$ retention interval. Data are mean + SEM. $\left({ }^{*}\right) P<0.05 ;\left(^{* *}\right) P<0.01 ;\left({ }^{* *}\right) P<0.001$.

platform crossing and fewer number of platform crossings at the $4 \mathrm{~d}$ test compared with their performance at the $1 \mathrm{~d}$ test, suggesting some degradation of spatial memory at the longer retention interval. Slower latencies to find the platform during acquisition in the aged rats could be associated with diminished encoding, and thus could explain their reduced performance on these two measures at the later interval test, but this does not explain the reduced performance of the young rats. Therefore, the slower latencies at acquisition likely did not play a significant negative role in spatial memory of the aged rats. Taken together, this $1 \mathrm{~d}$ training protocol can be used to compare how other variables (infection, surgery, and injury) might differentially influence long-term retention performance of young and aged rats. It is important to note however, that aged rats of a different strain may yield different results. The Fischer 344 rat strain for example, which is known for its accelerated aging, showed spatial memory declines in the water maze task as early as 12 mo of age (Guidi et al. 2014). Therefore, the use of this $1 \mathrm{~d}$ training protocol would have to be verified with other strains of rats.

Interestingly, when training was compressed into two sessions (Experiment 3 ), retention was only robust in the young rats, and only at the $1 \mathrm{~d}$ retention interval. Memory for the location of the platform was degraded by $4 \mathrm{~d}$ in the young rats, and was not apparent in the aged rats at either retention interval. These data suggest that this protocol should only be used under these limitations parameters.

Although there were some difference in the training parameters used in the present experiments and those used by Bolding and Rudy (2006) the results were generally consistent with their finding that an ISI of about $2 \mathrm{~h}$ produced robust retention.

\section{Acknowledgments}

This work was supported by grants from the National Institute on Aging R01AG028271 to R.M.B., L.R.W., and S.F.M. The authors wish to thank Ms. Vanessa Thompson and Ms. Shaelyn Silverman for their technical assistance with this study.

\section{References}

Barrientos RM, Higgins EA, Biedenkapp JC, Sprunger DB, Wright-Hardesty KJ,

Watkins LR, Rudy JW, Maier SF. 2006.

Peripheral infection and aging interact to impair hippocampal memory consolidation. Neurobiol Aging 27: 723-732.

Barrientos RM, Frank MG, Hein AM, Higgins EA, Watkins LR, RudyJW, Maier SF 2009a. Time course of hippocampal IL-1 $\beta$ and memory consolidation impairments in aging rats following peripheral infection. Brain Behav Immun 23: 46-54.

Barrientos RM, Watkins LR, Rudy JW, Maier SF. 2009b. Characterization of the sickness response in young and aging rats following E. coli infection. Brain Behav Immun 23: 450-454.

Barrientos RM, Hein AM, Frank MG, Watkins LR, Maier SF. 2012. Intracisternal interleukin-1 receptor antagonist prevents postoperative cognitive decline and neuroinflammatory response in aged rats. $J$ Neurosci 32: 14641-14648.

Bolding K, Rudy JW. 2006. Place learning in the Morris water task: making the memory stick. Learn Mem 13: 278-286.

Cunningham C, Sanderson DJ. 2008. Malaise in the water maze: untangling the effects of LPS and IL-1beta on learning and memory. Brain Behav Immun 22: 1117-1127.

Guidi M, Kumar A, Rani A, Foster TC. 2014. Assessing the emergence and reliability of cognitive decline over the life span in Fisher 344 rats using the spatial water maze. Front Aging Neurosci 6: 2.

Kraemer PJ, Brown RW, Baldwin SA, Scheff SW. 1996. Validation of a single-day Morris Water Maze procedure used to assess cognitive deficits associated with brain damage. Brain Res Bull 39: 17-22.

Received July 13, 2016; accepted in revised form September 20, 2016. 


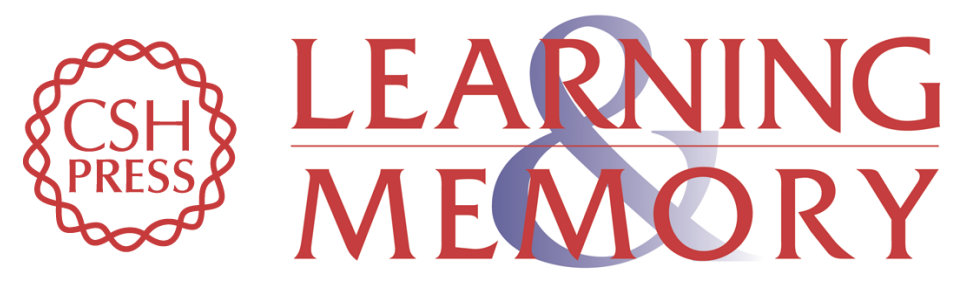

\section{Stable, long-term, spatial memory in young and aged rats achieved with a one day Morris water maze training protocol}

Ruth M. Barrientos, Meagan M. Kitt, Heather M. D'Angelo, et al.

Learn. Mem. 2016, 23:

Access the most recent version at doi:10.1101/Im.043489.116

\begin{aligned} & \hline References $\begin{array}{l}\text { This article cites } 8 \text { articles, } 2 \text { of which can be accessed free at: } \\ \text { http://learnmem.cshlp.org/content/23/12/699.full.html\#ref-list-1 }\end{array} \\ & \begin{array}{r}\text { Creative } \\ \text { Commons } \\ \text { License }\end{array} \begin{array}{l}\text { This article is distributed exclusively by Cold Spring Harbor Laboratory Press for the } \\ \text { first } 12 \text { months after the full-issue publication date (see } \\ \text { http://learnmem.cshlp.org/site/misc/terms.xhtml). After } 12 \text { months, it is available under } \\ \text { a Creative Commons License (Attribution-NonCommercial } 4.0 \text { International), as } \\ \text { described at http://creativecommons.org/licenses/by-nc/4.0/. }\end{array} \\ & \begin{array}{c}\text { Receive free email alerts when new articles cite this article - sign up in the box at the } \\ \text { top right corner of the article or click here. }\end{array} \\ & \begin{array}{c}\text { Service } \\ \text { terting }\end{array}\end{aligned}$

